\title{
Transient loss of peripheral vision as the presentation of left atrial myxoma
}

\author{
J Bolo-deoku Jr, R T Orchard, P N Fison
}

Ophthalmic Department, Sutton Hospital, Sutton, Surrey SM2 5NF

J Bolo-deoku Jr R T Orchard P N Fison

Correspondence to: P Fison, FRCS.

Accepted for publication 4 July 1991

\begin{abstract}
A 42-year-old man developed transient loss of vision in both eyes. On echocardiography to investigate a systolic murmur and determine the potential source of emboli, a large left atrial myxoma was diagnosed. This was removed successfully leaving no visual or neurological deficit.
\end{abstract}

\section{Case report}

A 42-year-old builder presented with sudden loss of vision in the lower temporal quadrant of his right eye lasting for 10 minutes with full recovery. A similar episode lasting 5 minutes

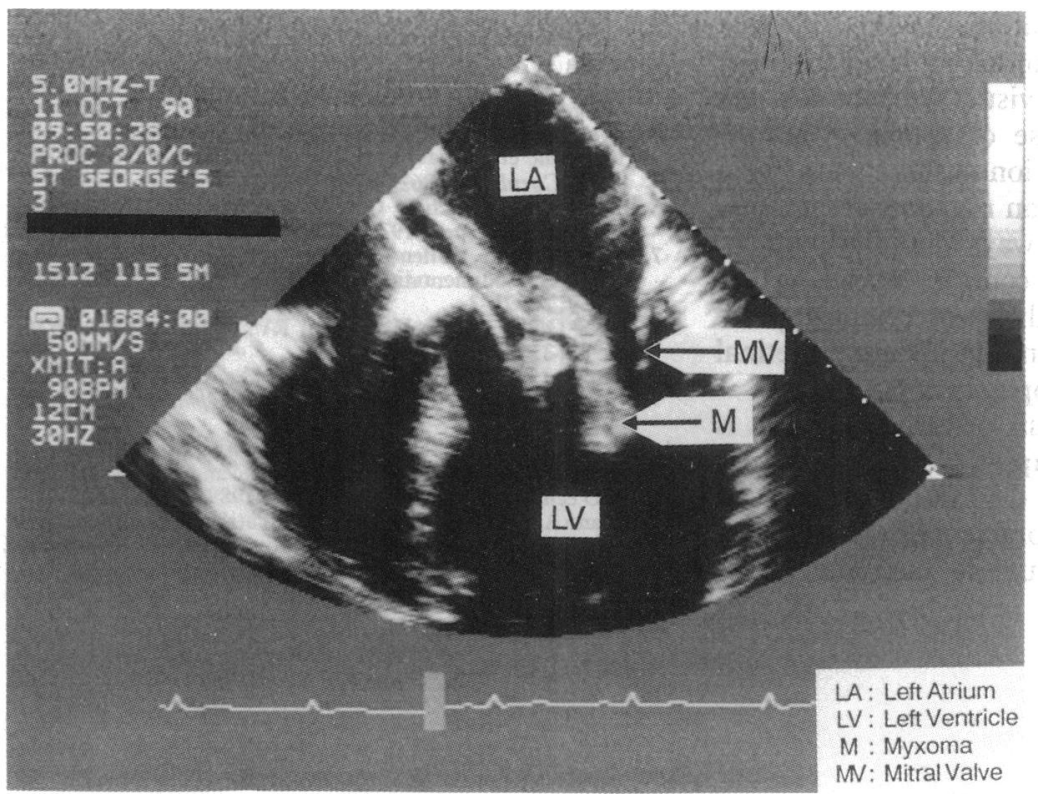

Figure 1 Transoesophageal echo image of the parasternal long axis of the heart. The atrial myxoma $(M)$ is seen prolapsing through the mitral valve $(M V)$ into the left ventricle $(L V)$.

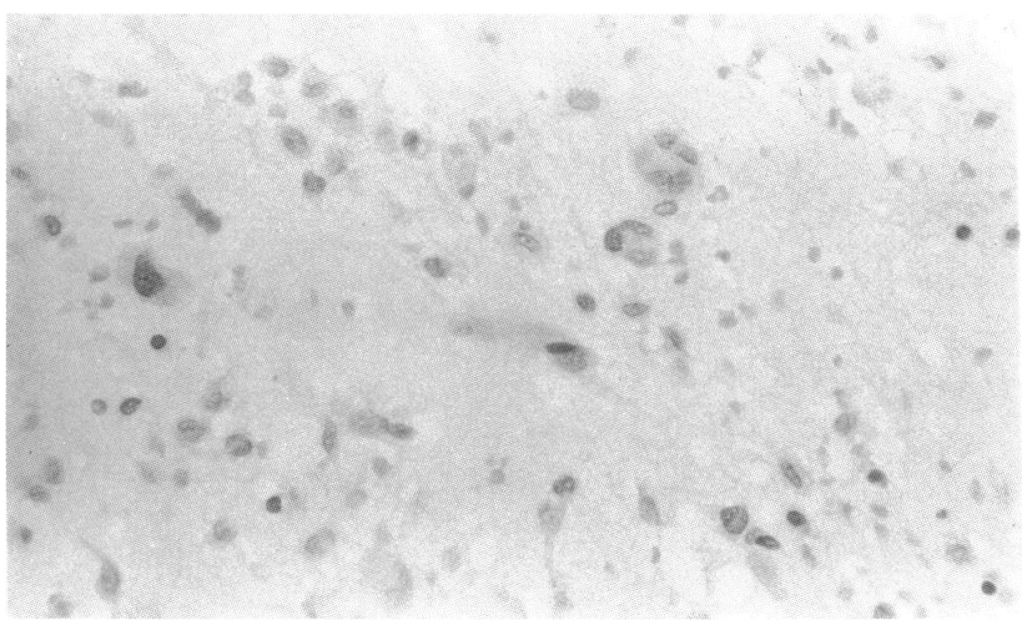

Figure 2 Microscopic appearance of atrial myxoma removed from patient, showing polygonal cells surrounded by abundant stroma. affected the upper temporal quadrant of the left eye the next day. He described transient pain in his knuckles at the same time that he was aware of blurred vision. Direct questioning established a history of rheumatic fever at the age of 5 years.

On examination he was an obese male Caucasian with no jaundice, cyanosis, purpuric rashes, splinter haemorrhages, or digital clubbing. His pulse was 80 and regular, and his blood pressure was $120 / 90 \mathrm{~mm} \mathrm{Hg}$. In addition to normal first and second heart sounds he had a harsh apical systolic murmur. All peripheral pulses were palpable and his chest was clinically clear. The central nervous system was normal. His visual acuity was $6 / 5$ without correction in both eyes and the visual fields were full. Fundus examination showed no features of embolism or retinal ischaemia. Investigations included a chest $x$ ray, electrocardiogram, erythrocyte sedimentation rate, full blood count, lipid profile, serum electrolytes and urea, blood cultures, and thyroid function tests, which were all normal. Urine analysis revealed blood ++++ and protein ++ but midstream urine microscopy and culture were negative. Carotid Doppler echography showed a higher than normal peak systolic frequency in the left external carotid artery. His echocardiogram demonstrated a large mobile mass prolapsing through the mitral valve (Fig 1). A pedunculated cylindrical myxoma, 15 $\mathrm{cm}$ long, was surgically removed from the left atrium (Fig 2).

Two months later the visual acuity remained normal at $6 / 5$ in each eye. Fundus examination revealed several minute superficial retinal haemorrhages just behind the ora serrata in both eyes. A small choroidoretinal scar was identified in the mid-periphery of the retina at the 10 o'clock meridian in the right eye.

\section{Discussion}

Primary cardiac tumours are themselves very rare, and of these the commonest is atrial myxoma (50\%). Though they are said to be benign tumours metastatic deposits have been widely reported. Grossly, myxomas are soft, polypoid, pale, lobulated masses often attached by a stalk to the atrial septum close to the foramen ovale. Seventy five per cent of cardiac myxomas arise from the left atrium. ${ }^{12}$ Microscopically, round, polygonal, or stellate cells are seen surrounded by abundant loose stroma rich in acid mucopolysaccharides. Atrial myxomas have been described in all age groups, with the greatest incidence between 30 and 60 years. The organ affected by embolism governs the mode of presentation of atrial myxoma and its severity. Retinal embolism from atrial myxoma is rare. ${ }^{3+}$ Transient peripheral visual loss in association 
with atrial myxoma has not been described previously. The most frequent sites for systemic embolism are the brain and kidneys. ${ }^{5}$ Renal tissue damage would explain the results of urine analysis in our patient.

The auscultatory signs of atrial myxoma consist of variations in the intensity of the first and second heart sounds, while possible murmurs vary from systolic and late diastolic to pansystolic murmurs. ${ }^{6}$ Features associated with atrial myxoma include chest pain, pyrexia, weight loss, arthralgia, and fatigue. Other abnormal findings include anaemia, polycythaemia, an elevated ESR, and raised plasma globulin levels. However, biochemical and haematological tests are not specific in establishing the diagnosis of atrial myxoma, as they are abnormal in only half of all those patients who present with constitutional symptoms. ${ }^{78}$ This patient's only specific constitutional symptom was transient knuckle pain. His positive clinical findings were an apical systolic murmur, haematuria, and proteinuria. The abnormal flow pattern in the left external carotid artery showed very little improvement after surgical intervention. In retrospect the history of rheumatic fever was probably incorrect as atrial myxoma may mimic its clinical presentation.

The absence of early fundus signs is consistent with the transience of the visual symptoms in this patient. The likely cause of transient branch retinal arteriolar obstruction in this case is fibrin platelet emboli rather than myxoma fragments. Fundal changes are not always identified, even in cases presenting with central retinal artery occlusion. ${ }^{9}$ We ascribe the subsequent appearance of fundal changes in our patient to retinal ischaemia at the time of open heart surgery.

The definitive diagnosis of atrial myxoma is made by echocardiography. Small myxomas remaining in the atrium during systole may be missed using a transthoracic approach alone. Therefore it is now usual to combine trans- thoracic and transoesophageal two-dimensional studies, both to establish the precise diagnosis and to determine the best surgical approach. ${ }^{1011}$

\section{Conclusion}

The diagnosis of atrial myxoma is difficult, due to the rarity of the condition, its variable clinical presentation and physical signs, and the lack of specific laboratory findings. Although retinal embolism from atrial myxoma is uncommon, full cardiac screening is justifiable with ocular symptoms alone, even in the absence of neurological signs. With the early diagnosis of atrial myxoma it is now possible to resect the tumour, thereby avoiding the onset of a massive stroke or death, and allowing full recovery for the patient.

The authors thank Dr C Pumphrey, Mr G Leach and the cardiac The authors thank Dr C Pumphrey, Mr G Leach and the cardiac echocardiograph, and Professor M J Davies of the Department of Histopathology for providing histological slides.

1 Prichard FRW. Tumours of the heart; review of the subject and report of one hundred and fifty cases. Arch Path 1951; 51: $98-128$.

2 Chao DH, Henry MG, Rosenberg HS. Myxoma of the heart with internal carotid artery occlusion in a child. Neurology 1960; 10: 418-22.

3 Yasuma F, Tauiuki M, Yasuma T. Retinal embolism from left atrial myxoma. Fpn Heart $\mathcal{F} 1989$; 30: 527-32.

4 Arruga J, Sanders MD. Ophthalmic findings in 70 patients with evidence of retinal embolism. Ophthalmology 1982; 89: 1336-47.

5 Silverman J, Olwin JS, Graettinger JS. Cardiac myxomas with systemic embolization: review of literature and report of a case. Circulation 1962; 26: 99-103.

6 Bulkely BH, Hutchins GM. Atrial myxomas. A fifty year review. Am Heart f 1979; 979: 639-43.

7 MacGregor GA, Cullen RA. The syndrome of fever, anaemia and high sedimentation rate with an atrial myxoma. $B M F$ 1959; 2: 991-3.

8 Miller GAH, Paneta M, Gibson RV. Atrial myxoma. BMf 1968; 3: 537-8.

9 Jampol LM, Wong AS, Albert DM. Atrial myxoma and central retinal artery occlusion. Am $\mathcal{f}$ Ophthalmol 1973; 75: 242-9.

10 Engberding R, Lis W, Dender F. Diagnosis of intra and pericardial tumour with transthoracic and transoesophageal 2Dechocardiography. Pol Tyg Lek 1989; 23: 551-3.

11 Milano A, Dan M, Dortolotti D. Left atrial myxoma's excision guided by transoesophageal cross sectional echocardiography. Int $f$ Cardiol 1990; 27: 125-7. 